\title{
$\beta$-Adrenergic Antagonism Alters the Behavioral and Neurochemical Responses to Cocaine
}

\author{
Glenda C. Harris, Mohsen A. Hedaya, Wei-Jian Pan, and Peter Kalivas, Ph.D.
}

The effects of the $\beta$-adrenergic antagonist propranolol on the locomotor stimulating, neurochemical, and reinforcing effects of cocaine were examined in rats. In Experiment 1 , propranolol (1, 3 and $10 \mathrm{mg} / \mathrm{kg}, \mathrm{IP})$ produced a dosedependent increase in the motor stimulant effects of cocaine without affecting basal motor activity. Atenolol, a peripherally restricted $\beta_{1}$ antagonist, and $(+)$ propranolol, the inactive isomer of propranolol, did not alter cocaine-induced locomotion. In Experiment 2, propranolol was shown to augment significantly the increase in extracellular dopamine content in the nucleus accumbens that accompanies a cocaine challenge. Experiment 3 demonstrated that propranolol produced a dose-dependent decrease in cocaine self-administration. Atenolol $(10 \mathrm{mg} / \mathrm{kg}$, $I P$ ) reduced cocaine self-administration but to a much lesser extent than propranolol. Experiment 4 demonstrated that coadministration of propranolol and cocaine did not alter the levels of cocaine in the brain and plasma achieved by cocaine administration alone. These data suggest that the blockade of $\beta$-adrenergic receptors potentiates cocaine-induced elevation of dopamine transmission in the nucleus accumbens, which is associated with an increase in cocaine-induced motor activity and a decrease in cocaine self-administration.

[Neuropsychopharmacology 14:195-204, 1996]
KEY WORDS: Cocaine; Propranolol; Dopamine; Locomotion; Self-administration; Dopamine

It is generally accepted that the mesoaccumbens dopamine system, which encompasses dopamine projections from the ventral tegmental area to the nucleus accumbens (Dahlstrom and Fuxe 1964; Swanson 1982), plays a major role in the locomotor stimulant and reinforcing effects of cocaine (Kalivas and Stewart 1991; Kelly and Iversen 1975; Koob and Bloom 1988; Pettit et al. 1984; Roberts and Koob 1982; Wise and Rompre 1989; Zito et al. 1985). This is indicated primarily by the fact that cocaine increases mesolimbic dopamine transmission via

From the Alcohol and Drug Abuse Program (CGH, PK) and the Department of Pharmaceutical Sciences (MAH), Washington State University, Pullman, WA.

Address correspondence to Peter Kalivas, Ph.D., Alcohol and Drug Abuse Program, Department VCAPP, Washington State University, Pullman, WA 99164-6520.

Received February 14, 1995; revised May 1, 1995; accepted May 12,1995 blockade of dopamine presynaptic reuptake (Akimoto et al. 1989; Kalivas and Duffy 1993; Pettit et al. 1990; Reith et al. 1986; Ritz et al. 1990). Although most pharmacological treatments tested in animal models have targeted dopamine transmission (Caine and Koob 1993; Goeders et al. 1989; LaCosta and Roberts 1993), cocaine also inhibits reuptake and increases the synaptic concentrations of norepinephrine and serotonin (Kuczenski and Segal 1988; Parsons and Justice, 1993; Reith et al. 1986; Ritz et al. 1990).

$\beta$-adrenergic blockers have been shown to be effective at decreasing cocaine-reinforced responding in squirrel monkeys (Goldberg and Gonzalaz 1976) and in alleviating anxietylike behaviors associated with withdrawal from chronic cocaine administration in rodents (Harris and Aston-Jones 1994). $\beta$-adrenergic antagonists have also been used successfully in treating alcohol withdrawal symptoms in humans (Carlsson 1976). Furthermore, a pharmacological treatment for cocaine abuse is tricyclic antidepressants, which decrease cocaine use 
and craving (Gawin 1991). This chemical class of antidepressants causes a downregulation of $\beta$-adrenergic receptors and the time course for the efficacy of the tricyclics in cocaine treatment and $\beta$-receptor downregulation are similar (Crosby et al. 1991; Gawin 1991). Finally, an upregulation of $\beta$-adrenergic receptors has been reported to occur with chronic cocaine administration (Banerjee et al. 1979). Together, these studies pose the possibility that $\beta$-adrenergic receptors may play a role in the effects of acute and repeated cocaine administration.

To test this hypothesis the nonselective, lipophilic $\beta$-adrenergic antagonist propranolol or the lipophobic $\beta_{1}$ selective antagonist atenolol were administered to rats prior to an acute injection of cocaine and motor activity and extracellular levels of dopamine in the nucleus accumbens measured. In addition, propranolol was administered to animals trained to self-administer cocaine. Finally, because propranolol was found to alter all three effects of cocaine in a manner consistent with potentiating the biological actions of cocaine, the plasma and brain levels of cocaine were measured to determine whether propranolol altered cocaine disposition.

\section{MATERIALS AND METHODS}

\section{Subjects}

Male Sprague-Dawley rats from Simonsen (Gilroy, CA) weighing between 250 and $300 \mathrm{~g}$ were used in all experiments. Before and after surgery rats were group- or single-housed, respectively, in accordance with NIH guidelines and maintained on a 12-hour light/dark cycle with food and water available ad libitum.

\section{Drugs}

Cocaine $\mathrm{HCl}$ was provided by the National Institute on Drug Abuse and dissolved in $0.9 \%$ sterile saline. Propranolol and atenolol were purchased from Sigma Chemical Company (St Louis, MO) and dissolved in sterile distilled water. All vehicle injections consisted of sterile distilled water, and all drugs were administered via intraperitonal injection.

Experiment 1: Effects of Propranolol on the Acute Locomotor Response to Cocaine. Behavioral activity was monitored in photocell chambers (Omnitech Inst., Columbus, $\mathrm{OH}$ ) located in sound isolated boxes with individual air and light supply $(10 \mathrm{~W})$. Measures of total horizontal activity (breaking of adjacent photocell beams) were obtained at 20-minute intervals. All sessions were run with a 1-hour habituation of followed by a 2-hour drug test period. After the habituation period, a total of 49 rats were injected with either propranolol $(1,3$ or 10 $\mathrm{mg} / \mathrm{kg})$, atenolol $(10 \mathrm{mg} / \mathrm{kg}),(+)$ propranolol $(10 \mathrm{mg} /$ $\mathrm{kg}$ ), an inactive isomer, or water vehicle 10 minutes prior to receiving cocaine $(15 \mathrm{mg} / \mathrm{kg})$. This dose of cocaine is on the ascending limb of the dose-response curve for the induction of locomotor activity (Kalivas et al. 1988). In follow-up experiments the locomotor effects of each drug alone (propranolol $10 \mathrm{mg} / \mathrm{kg}$, IP, atenolol $10 \mathrm{mg} /$ $\mathrm{kg}$, IP, and (+) propranolol $10 \mathrm{mg} / \mathrm{kg}, \mathrm{IP}$ ) were compared to water vehicle injections $(1 \mathrm{ml} / \mathrm{kg}, \mathrm{IP})$. Behavior was monitored for 2 hours post-injection.

Experiment 2: Effects of Propranolol on Cocaine-Induced Dopamine Release in the Nucleus Accumbens Using In Vivo Dialysis. Fifteen rats were stereotaxically implanted (Equithesin anesthesia) with bilateral guide cannulae (20-gauge stainless steel tubing) in the nucleus accumbens (AP: $+1.7 \mathrm{~mm}$ from bregma, ML: $\pm 1.3 \mathrm{~mm}$, DV: $-5.3 \mathrm{~mm}$ from dura) 5 days prior to dialysis. Dialysis probes with an active membrane region $250 \mu \mathrm{m}$ in diameter and $3 \mathrm{~mm}$ in length were attached and extended $3 \mathrm{~mm}$ below the guide cannulae (Robinson and Whishaw 1988). The probes were inserted through one of the guide cannulae the night before the experiment. The next day dialysis buffer ( $5 \mathrm{mM} \mathrm{KCl} ; 120 \mathrm{mM} \mathrm{NaCl} ; 1.4 \mathrm{mM} \mathrm{CaCl}_{2}$; $1.2 \mathrm{mM} \mathrm{MgCl}_{2} ; 5 \mathrm{mM}$ glucose; plus $0.2 \mathrm{mM}$ phosphatebuffered saline to give a $\mathrm{pH}$ value of 7.4 and a final sodium concentration of $120.7 \mathrm{mM}$ ) was advanced through the probe at a rate of $1.9 \mu \mathrm{l} /$ minute (Harvard Inst., Boston, MA) for 2 hours. Baseline samples were collected for 1 hour and 40 minutes, after which rats were injected with either propranolol $(10 \mathrm{mg} / \mathrm{kg}, \mathrm{IP})$ or vehicle. Ten minutes later all rats were given cocaine (15 $\mathrm{mg} / \mathrm{kg}, \mathrm{IP}$ ) and samples were collected for 2 hours. In a separate experiment the effects of propranolol alone on dopamine levels in the accumbens were tested. In these experiments the same number of baseline samples were collected, then animals were given a vehicle injection and samples were collected for 1 hour and 20 minutes. Following this period, propranolol was injected (10 $\mathrm{mg} / \mathrm{kg}$ ) and samples were collected for an additional 1 hour and 20 minutes.

All dialysis samples were collected into $20-\mu l$ mobile phase containing 2 pmol dihydroxybenzylamine as an internal standard. At the end of 10 experiments, probe recovery was determined to be $7.3 \pm 2.4 \%$ by placing the probe for 20 minutes in the dialysate buffer containing dopamine $\left(10^{-7} \mathrm{M}\right)$. The concentrations of dopamine, 3,4-dihydroxyphenylacetic acid (DOPAC), and homovanillic acid (HVA) were measured using HPLC with coulometric electrochemical detection as previously described (Sorg and Kalivas 1991). Dopamine peaks were recorded on a chart recorder and compared to an external standard curve (10 to $100 \mathrm{fmol}$ ).

Experiment 3: Effects of Propranolol on Cocaine and Food Self-Administration Behavior. Thirteen rats were individually housed and maintained on a 12-hour reversed light-dark cycle (lights on 7:00 P.M. to 7:00 A.M.). Rats 
were initially trained to lever-press for food before being surgically implanted with a chronic jugular catheter using a method similar to that reported by Hubner and Koob (1990). Following 24 hours of food deprivation, rats were placed in the operant chambers with two operational levels (Med-Assoc., East Fairfield, VT). Each rat was assigned to be reinforced for presses on either the right or left lever (half each) and food pellets were taped to the correct lever. Each rat was allowed to self-train and press for 100 pellets (45-mg Noyes) before being returned to ad libitum food.

Following acquisition of lever-pressing behavior, rats were surgically implanted with a chronic silastic catheter in the right jugular vein under Equithesin anesthesia (pentobarbital and chloral hydrate). The catheter consisted of silastic tubing attached to a guide cannula bent at a right angle with a screw on mount that allowed the catheter to be closed with a removable plastic screw top (20 ga, Plastics One, Roanoke, VA). The tubing-guide cannula junction was glued and the guide cannula was then attached to a 1-inch square of marlex mesh with dental acrylic. The catheter was passed subcutaneously from a 2-mm incision on the rat's back to the isolated jugular vein for implantation. The marlex mesh/catheter assembly was then attached subcutaneously to the back muscles with super glue. Silk sutures were used to close all wounds. Heparinized saline was used to flush the catheters daily to prevent clogging.

Four days after surgery, rats were placed back in the operant chambers and allowed to self-administer cocaine. The rats were attached to the syringe pumps by means of a connector and fluid swivel (3-hour sessions, 5 days per week, 12:00 P.M.-3:00 P.M.). Rats were maintained throughout the experiment on a fixed-ratio 1 (FR 1, continuous reinforcement) schedule. Each lever press on the active lever resulted in a $0.05-\mathrm{ml}$ intravenous infusion of cocaine ( $0.33 \mathrm{mg}$ per infusion) administered over 3 seconds. A red signal light mounted over the active lever indicated the onset of an injection and remained lit for a 20-second time-out period after each injection. Presses on the inactive lever were counted but had no consequence.

After stable baseline responding for cocaine was established ( $\pm 10 \%$ of average for 3 consecutive days) rats were pretreated 10 minutes prior to beginning a session with either propranolol ( 5 or $10 \mathrm{mg} / \mathrm{kg}$, IP) or vehicle. All rats were tested with each dose in random order. At least 3 days of stable baseline responding separated each test day.

Twenty-four hours after the last self-administration session, rats were placed into photocell cages (see above for a description of the apparatus) to measure the locomotor response to propranolol. Following a 1-hour habituation period, rats were injected with either vehicle or propranolol $(10 \mathrm{mg} / \mathrm{kg}, \mathrm{IP})$ and locomotor activity was monitored for 2 hours.
In a separate group of rats, the effects of the peripheral $\beta_{1}$ antagonist atenolol was tested on cocaine selfadministration behavior. Atenolol was used as a partial control for peripheral actions by propranolol. Atenolol and propranolol have identical efficacy in blocking the tachycardia accompanying cocaine administration (Schindler et al. 1992), but atenolol crosses the blood-brain barrier in relatively limited quantities (Agon et al. 1991). The methods and procedures were the same as those outlined except that on test days animals were injected with either atenolol $10 \mathrm{mg} / \mathrm{kg}$ or vehicle.

Six animals were food-trained as described. Once animals were trained (pressed for 100 reinforcers), they were maintained at $90 \%$ of their free feeding weight for the remainder of the experiment. Once stable baseline responding for food occurred ( 3 days, FR 1), animals were injected with either propranolol $(10 \mathrm{mg} / \mathrm{kg}$, IP) or vehicle on alternating days.

Experiment 4: Plasma Levels of Cocaine. It was suggested by Goldberg and Gonzalaz (1976) that the capacity of propranolol to reduce cocaine-reinforced behavior in squirrel monkeys may arise from a propranolol-induced decrease in hepatic metabolism of cocaine. To evaluate this possibility, rats were adapted to photocell chambers for 60 minutes and injected with either saline $(1 \mathrm{ml} / \mathrm{kg}$, IP) or propranolol $(10 \mathrm{mg} / \mathrm{kg}, \mathrm{IP}) 10$ minutes prior to administering cocaine $(15 \mathrm{mg} / \mathrm{kg}, \mathrm{IP})$. The rats were returned to the photocell chamber and decapitated 30 minutes later. Trunk blood was collected in heparinized tubes containing $100 \mu$ l of saturated sodium fluoride solution and centrifuged. The brain was also removed, weighed, and homogenized in phosphate buffer, $\mathrm{pH}=$ 6.0 , containing $5 \%$ saturated sodium fluoride to make a final volume of $5 \mathrm{ml}$.

Plasma and brain homogenates $(300 \mu \mathrm{l})$ were added to Sorensen's phosphate buffer $(600 \mu \mathrm{l} ; \mathrm{pH}=6.0)$ containing bupivacaine $(4 \mu \mathrm{g} / \mathrm{ml})$ as an internal standard. The samples were extracted with chloroform $(7 \mathrm{ml})$ and the organic layer evaporated at $40^{\circ} \mathrm{C}$ under nitrogen. The residue was reconstituted in mobile phase $(75 \mu \mathrm{l} ; 10$ $\mathrm{mM}$ monobasic ammonium phosphate, $5 \mathrm{mM}$ TEA, $20 \%$ acetonitrile, $\mathrm{v} / \mathrm{v}, \mathrm{pH}=3.0$ ) and injected on to an HPLC system. Separation was achieved using a suelcosil deactivated ODS column (Supelco, Bellefonte, PA) and cocaine monitored at $235 \mathrm{~nm}$ with a variable-wavelength detector (Shimadzu SPD 10A, Columbia, MD). Cocaine concentration was quantified comparing integrated peak heights to an external standard curve.

\section{Histology and Data Analysis}

Animals from the dialysis experiment were killed with an overdose of sodium pentobarbital and perfused through the heart with $10 \%$ formalin. Brains were removed, sectioned $(100 \mu \mathrm{m})$, and stained with Cresyl violet to deter- 

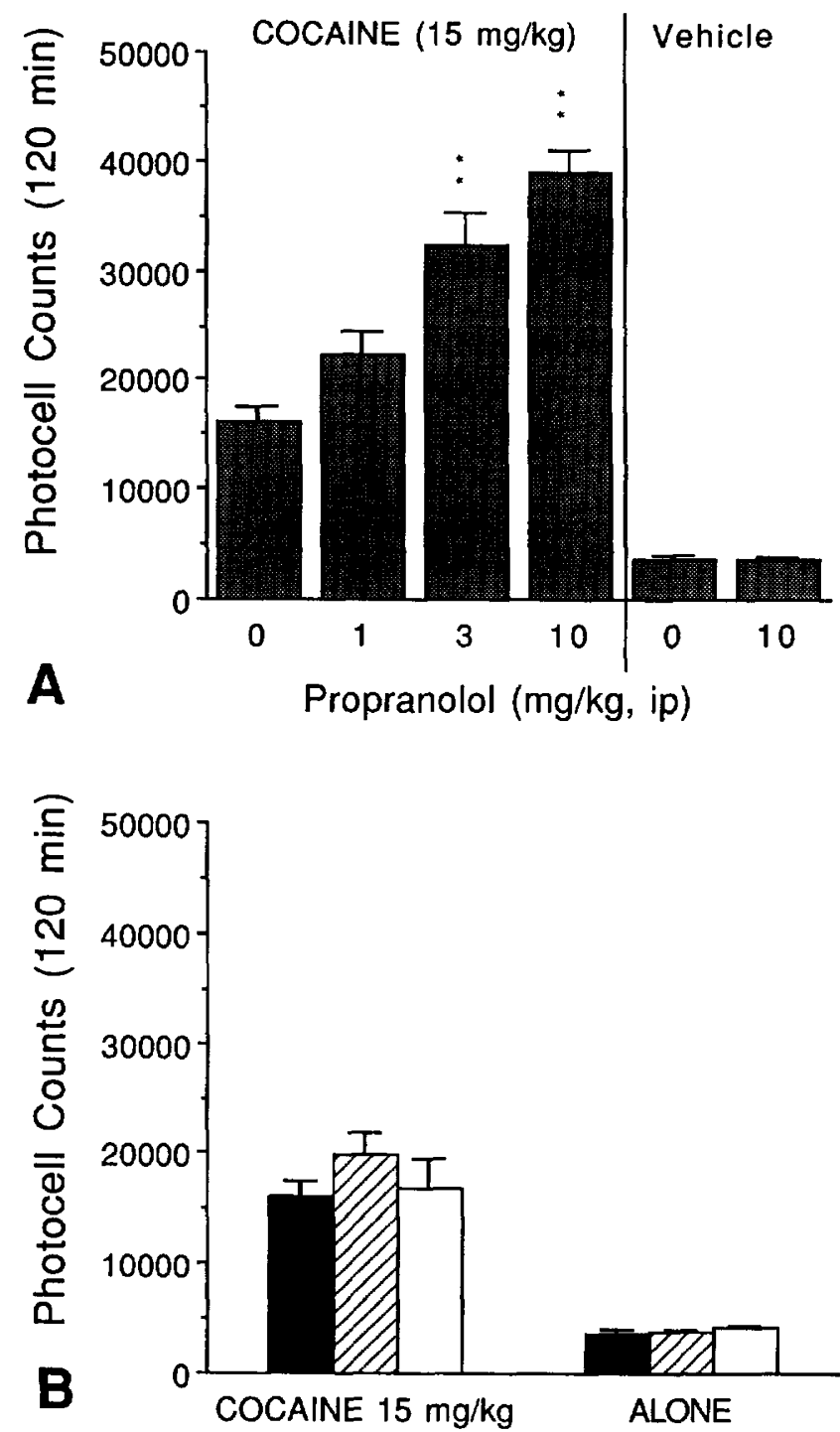

Figure 1. Interaction between propranolol and cocaineinduced motor activity. (A) The effects of different doses of propranolol on locomotor activity. Bars represent the mean number of photocell counts \pm SEM for total horizontal locomotor activity seen for 2 hours following either a cocaine injection (Cocaine, $15 \mathrm{mg} / \mathrm{kg}$ ) plus propranolol or injections of propranolol alone (Vehicle, 0 and $10 \mathrm{mg} / \mathrm{kg}$ ). $n>6$ in each treatment group. (B) The effects of atenolol $(10 \mathrm{mg} / \mathrm{kg})$ (striped bars) and (+) propranolol $(10 \mathrm{mg} / \mathrm{kg}$ ) (open bars) on locomotor activity (shaded bars are vehicle). Bars represent the mean number of photocell counts \pm SEM for total horizontal locomotor activity seen for 2 hours following either a cocaine injection (Cocaine, $15 \mathrm{mg} / \mathrm{kg}$ ) or injections of the drugs alone (Alone). $n>6$ in each treatment group. ${ }^{* *} p<.01$; compared to cocaine without propranolol pretreatment, using a oneway ANOVA followed by a least significant test for multiple comparisons.

mine the placement of the dialysis probes. Behavioral and neurochemical data were analyzed by either a twoway repeated-measures or one-way analysis of variance (ANOVA) where appropriate. Post hoc analysis for sta- tistical differences was performed using a paired $t$ - test with a Bonferoni adjustment to the probability levels or a least significant difference test.

\section{RESULTS}

\section{Experiment 1}

This experiment examined the interaction between cocaine and propranolol on the acute locomotor response to cocaine. Figure $1 \mathrm{~A}$ shows that propranolol pretreatment caused a dose-dependent increase in the acute locomotor response to cocaine $\left[\left(F_{(5,48)}=20.2, p<.0001\right]\right)$, with doses of 3 and $10 \mathrm{mg} / \mathrm{kg}$ being significantly different from vehicle $(p<.01)$. Neither atenolol nor $(+)$ propranolol pretreatment significantly altered the motor response to cocaine compared to saline vehicle pretreatment (Figure 1B). None of the drugs alone changed motor activity compared to vehicle pretreatment (Figure $1 \mathrm{~A}$ and $\mathrm{B}$ ).

Figure 2A shows the time course of the enhancement of the locomotor effects to cocaine following propranolol pretreatment $(10 \mathrm{mg} / \mathrm{kg})$. The propranolol-pretreated animals had significantly increased photocell counts relative to vehicle-pretreated animals throughout the 3-hour session.

\section{Experiment 2}

This experiment was designed to determine whether the capacity of propranolol to enhance the locomotor effects of cocaine was due to an enhancement of dopamine levels in the nucleus accumbens. Figure 2B demonstrates that propranolol pretreatment $(10 \mathrm{mg} / \mathrm{kg}$, IP) markedly elevated cocaine-induced increase in dopamine levels in the nucleus accumbens. At the peak of the response, propranolol pretreatment caused a threefold increase in dopamine levels above that normally produced by cocaine administration. The time course of this elevation is similar to the enhancement of the motor response (Figure $2 \mathrm{~A}$ and $\mathrm{B}$ ). Figure $2 \mathrm{C}$ shows that neither propranolol nor vehicle administration alone significantly elevated dopamine levels above baseline.

Figure 3 shows the location of the dialysis probe placements in Experiment 2. The active region of all probes was located medial to the anterior commissure with at least $50 \%$ passing through the nucleus accumbens. In addition, portions of the active region of the membrane were in the striatum and olfactory tubercle.

\section{Experiment 3}

The mean daily number of cocaine reinforcers was $36.8 \pm$ 2.6. Figure $4 \mathrm{~A}$ shows the effect of propranolol pretreatment (5 and $10 \mathrm{mg} / \mathrm{kg}$, IP) on cocaine-reinforced responding. Both doses of propranolol significantly 

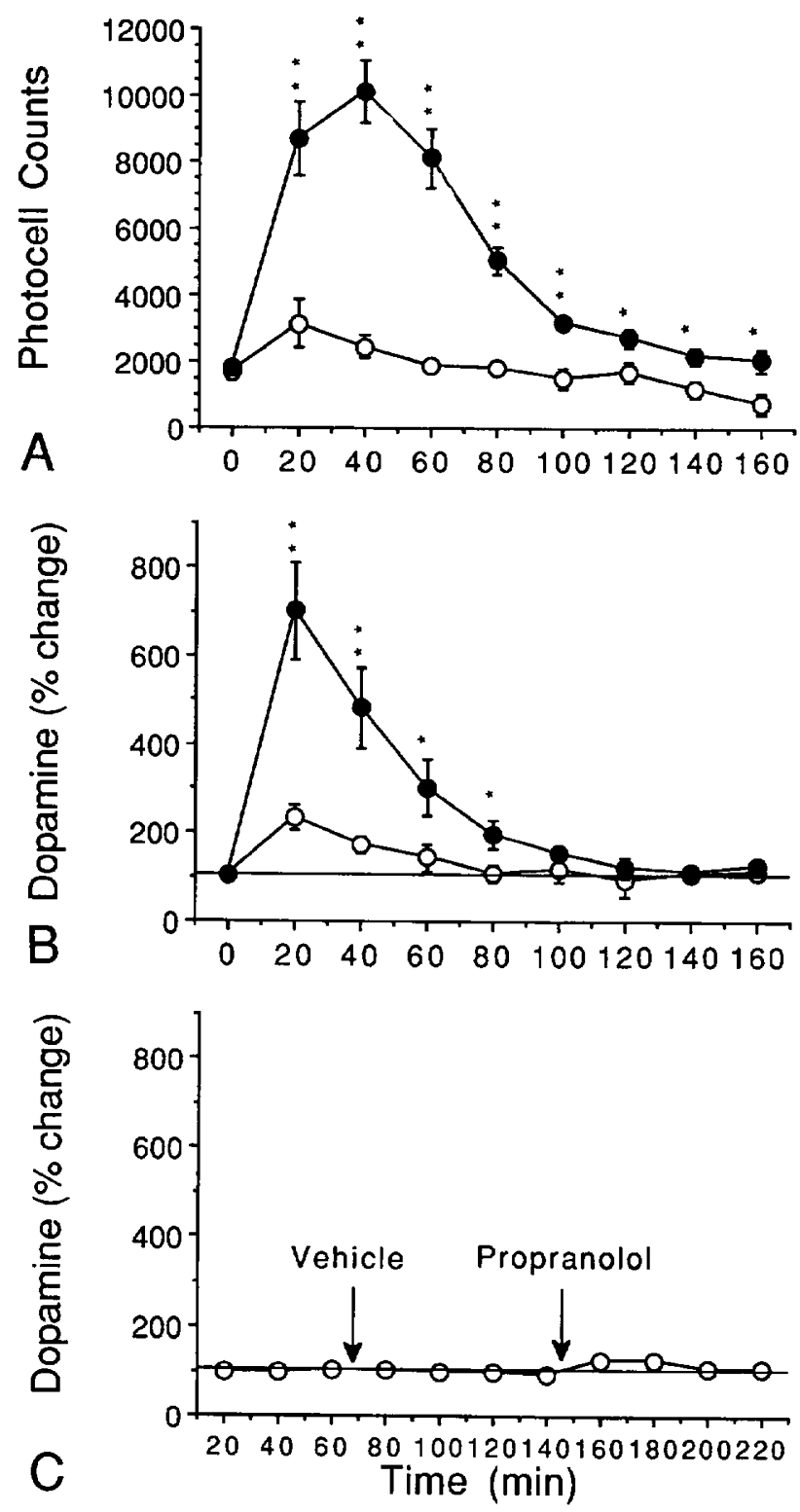

Figure 2. Effect of propranolol on cocaine-induced elevation in extracellular dopamine content in the nucleus accumbens ( $O$ vehicle, 0 propanol). (A) The effects of propranolol $(10 \mathrm{mg} / \mathrm{kg}, \mathrm{IP})$ on locomotor activity to cocaine $(15 \mathrm{mg} / \mathrm{kg}$, IP) plotted over time. Each point represents the mean \pm the standard error. Using a two-way repeated-measures ANOVA, treatment $F_{(1,4)}=81.65, p<.001$, time $F_{(8,112)}=34.92, p<$ .001 , interaction $F_{(8,112)}=17.68, p<.0001$. (B) The effects of propranolol $(10 \mathrm{mg} / \mathrm{kg}, \mathrm{IP})$ on the percent change from baseline for dopamine concentrations in the nucleus accumbens following a cocaine challenge $(15 \mathrm{mg} / \mathrm{kg}, \mathrm{IP})$. There was no difference in basal dopamine values (not corrected for recovery) between vehicle + cocaine $(92 \pm 30 \mathrm{fmol} / \mathrm{sample}, n=5)$ and propranolol + cocaine $(88 \pm 30 \mathrm{fmol} / \mathrm{sample}, n=5)$. Each point represents the mean \pm SEM. Using a two-way repeated-measures ANOVA, treatment $F_{(1,8)}=14.9, p<.001$; time $F_{(10,80)}=24.21, p<.001$, interaction $F_{(10,80)}=17.68, p<$ .001. (C) The effects of propranolol $(10 \mathrm{mg} / \mathrm{kg})$ and water vehicle on the percent change from baseline for dopamine concentrations in the nucleus accumbens. The arrows indi- reduced cocaine-reinforced responding without altering the number of time-out responses. Figure $4 \mathrm{~A}$ shows that the $10-\mathrm{mg} / \mathrm{kg}$ dose was more effective (16\% vs. $68 \%$ ) in reducing cocaine self-administration [propranolol, $5 \mathrm{mg} / \mathrm{kg}, t(5)=5.7, p<.05$; propranolol, $10 \mathrm{mg} /$ $\mathrm{kg}, t(7)=8.0, p<.0001]$. An analysis of the mean hourly intake of cocaine (Figure 4B) indicated that propranolol $(10 \mathrm{mg} / \mathrm{kg}$ ) significantly reduced responding at each time period [ 1 hour, $t(7)=4.9, p<.001 ; 2$ hours, $t(7)=7.8, p<.001 ; 3$ hours $t(7)=8.8, p<.001]$. The 5 -mg/kg dose did not significantly reduce responding from the vehicle level at any of the time points $(p>.8)$.

In order to determine whether the effects of propranolol were due to blockade of peripheral receptors we tested the effects on cocaine-reinforced responding by the $\beta_{1}$ antagonist atenolol ( $10 \mathrm{mg} / \mathrm{kg}$, Ip), which poorly crosses the blood-brain barrier. Although less so than propranolol, atenolol produced a consistent effect in decreasing cocaine-reinforced responding (12\% reduction; Figure 4A).

The effects of propranolol on food-reinforced responding were also examined. Propranolol $(10 \mathrm{mg} / \mathrm{kg})$ was found to produce a small but statistically reliable decrease in food-reinforced responding $\left[F_{(6,11)}=7.23, p<.05\right]$. The mean number of daily reinforcers for baseline and vehicle conditions was $195 \pm 14$. This decreased to $154 \pm 8$ food reinforcers following propranolol pretreatment. the magnitude of the suppression on food responding was less than that produced by propranolol on cocaine responding ( $20 \%$ versus $68 \%$ ).

\section{Experiment 4}

Table 1 shows that there was no difference in the plasma or brain levels of cocaine $(15 \mathrm{mg} / \mathrm{kg}, \mathrm{Ip})$ measured 30 minutes after injection between rats pretreated with saline or propranolol $(10 \mathrm{mg} / \mathrm{kg}$, Ip). In contrast, rats pretreated with propranolol demonstrated more horizontal photocell counts in response to cocaine than did control rats.

\section{DISCUSSION}

The nonselective $\beta$-antagonist propranolol produced a dose-related increase in cocaine-induced motor activity. This was associated with a significant augmentation in the increase in extracellular dopamine in the nucleus

cate when animals were injected with vehicle and propranolol. Each point represents the mean \pm SEM (note that SEM bars were smaller than the radius of the symbol; $n=5$ ). The basal value for dopamine was $52 \pm 16 \mathrm{fmol} / \mathrm{sample}$. Using a one-way repeated-measured ANOVA, there was no significant effect of saline or propranolol $\left(F_{(12,64)}=1.00, p=0.466\right)$. ${ }^{*} p<.05,{ }^{* *} p<.01$, using a two-tailed Student's $t$-test for comparisons between treatment groups with probability adjustments using the Bonferoni method. 
Figure 3. Histological identification of the dialysis probe placements from Experiment 2 (corresponding to data in Figure 2). The drawings were adapted from the atlas of Paxinos and Watson (1986).
Figure 4. Interaction between propranolol, atenolol, and the self-administration of cocaine. (A) The effects of propranolol (5 and $10 \mathrm{mg} / \mathrm{kg}, \mathrm{IP}$ ) and atenolol $(10 \mathrm{mg} / \mathrm{kg}$, IP) on cocaine-reinforced responding. The bars represent the mean number of cocaine-reinforced responses \pm SEM during the entire 3-hour session. Baseline refers to an average of four baseline sessions during the course of the experiment. For propranolol, using a one-way ANOVA, $F_{(2,19)}=$ $28.13, p<.001$. For atenolol, $F_{(5,9)}=18.9$ $p<.05$. (Open bars, baseline; shaded bars, vehicle; striped bars, $5 \mathrm{mg} / \mathrm{kg}$; solid bars, $10 \mathrm{mg} / \mathrm{kg}$.) (B) The mean hourly intake of cocaine \pm SEM over the 3-hour session following pretreatment with either vehicle or propranolol. Using a two-way repeated-measures ANOVA, treatment $F_{(2,19)}=28.37, p<.001$, time $F_{(2,38)}=$ $10.68, p<.001$, interaction $F_{(2,38)}=, 1.83$, $p=.14 .{ }^{*} p<.05$, ${ }^{* *} p<.01$; using a paired $t$-test with a Bonferoni adjustment for multiple comparisons. ( $O$ Vehicle, $5 \mathrm{mg} / \mathrm{kg}, \mathbf{\square} 10 \mathrm{mg} / \mathrm{kg}$.)
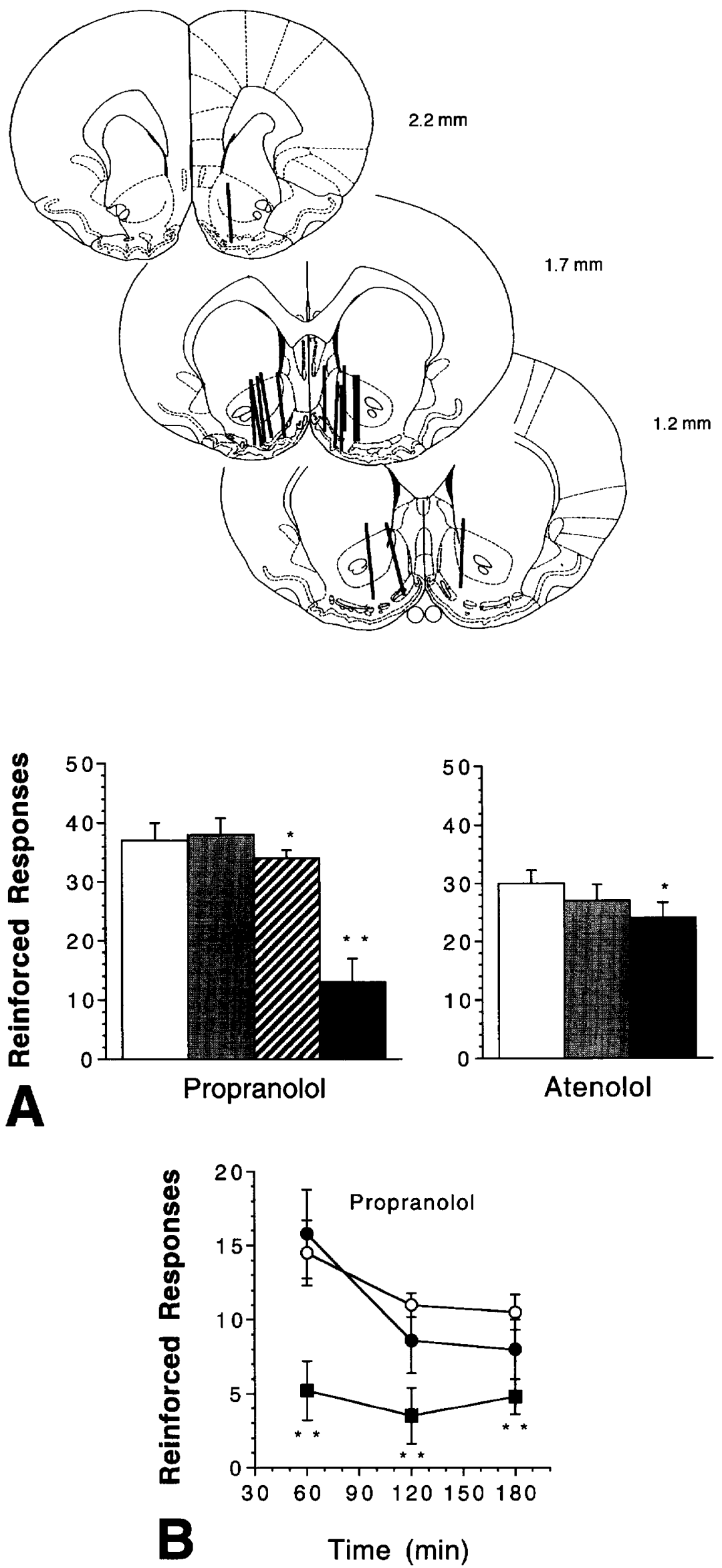
Table 1. Effect of Propranolol on the Levels of Cocaine in Brain and Plasma

\begin{tabular}{lcccc}
\hline Treatment & $\boldsymbol{n}$ & $\begin{array}{c}\text { Photocell } \\
\text { Counts }\end{array}$ & $\begin{array}{c}\text { Plasma } \\
\text { (ng/ml) }\end{array}$ & $\begin{array}{c}\text { Brain } \\
\text { (ng/gm) }\end{array}$ \\
\hline Water + cocaine & 8 & $11,954 \pm 1,084^{*}$ & $740 \pm 102$ & $3,454 \pm 426$ \\
Propranolol + cocaine & 9 & $18,696 \pm 2,967$ & $881 \pm 139$ & $3,936 \pm 661$ \\
\hline
\end{tabular}

Rats were pretreated with water or propranolol $(10 \mathrm{mg} / \mathrm{kg}, \mathrm{IP}) 10$ minutes prior to injecting cocaine $(15 \mathrm{mg} / \mathrm{kg}, \mathrm{IP})$. Thirty minutes later the rats were killed. The data are shown as mean $\pm \mathrm{SEM}$.

${ }^{*} p<.05$, comparing the two treatment groups using a Student's $t$-test.

accumbens following an acute injection of cocaine. The fact that propranolol did not alter the brain or plasma concentration of cocaine 30 minutes after injection argues that the potentiation by propranolol does not result from alterations in the disposition of cocaine. In addition, propranolol produced a dose-dependent reduction in cocainereinforced responding.

\section{Motor Activity and Extracellular Dopamine}

Numerous data suggest that increased accumbal dopamine transmission plays a significant role in mediating the enhanced locomotor response to psychostimulants (see Kalivas et al. 1993; Le Moal and Simon 1991; Mogenson et al. 1993 for reviews). In the current experiment, we found that dopamine levels in the accumbens increased an average of $700 \%$ over baseline levels in the presence of combined cocaine and propranolol. Similar to previous reports, dopamine levels increased only $200 \%$ to $250 \%$ over baseline following cocaine administration alone (Hooks et al. 1992; Kalivas and Duffy 1993; Patrick et al. 1991; Pettit and Justice 1990). Therefore, the capacity of propranolol to enhance cocaine-induced elevation in dopamine levels in the nucleus accumbens is likely to be mediating the enhanced locomotor response to cocaine produced by pretreatment with propranolol. Supporting this contention, the time course of the enhanced locomotor effect to cocaine in the presence of propranolol approximately paralleled the time course of the enhanced dopamine response to cocaine.

\section{Self-Administration of Cocaine}

In addition to locomotor activity, mesoaccumbens dopamine transmission is thought to be critical in the initiation and maintenance of cocaine self-administration (see Dworkin and Smith 1992; Koob 1992; Le Moal and Simon 1991; Wise and Rompre 1989; for reviews). For example, enhanced extracellular dopamine in the nucleus accumbens is associated with a reduction in cocainereinforced behavior (Pettit and Justice 1990), while low doses of dopamine blockers increase the rate of cocaine self-administration behavior (deWitt and Wise 1977; Roberts and Vickers 1984). Thus, the capacity of propranolol to augment cocaine-induced elevation in accumbal extracellular dopamine most likely mediated the inhibition of cocaine self-administration. An alternative explanation is that propranolol produced a generalized decrease in locomotor activity. This is not likely because propranolol alone did not decrease motor behavior relative to vehicle administration or, in the presence of cocaine, propranolol elevated motor activity. Propranolol also decreased food-reinforced responding, albeit substantially less than it reduced cocaine-reinforced behavior. It is possible that the decrease in food-reinforced responding could be related to the decrease in cocaine responding. In the present experiments the rats were eating a sucrose-based food pellet. As sucrose elevates accumbal dopamine levels (Heffner et al. 1980), it is possible that propranolol enhanced the dopamine-stimulating effect of sucrose, thereby decreasing the number of desired reinforcers.

The reduction by propranolol in cocaine self-administration behavior is similar to that reported by Goldberg and Gonzalaz (1976) in squirrel monkeys. In that study propranolol had no effect on food-reinforced responding but significantly decreased cocaine-reinforced responding. It was suggested by these authors that because propranolol decreases cardiac output it may reduce the hepatic metabolism of cocaine. We found no evidence that propranolol alters brain or plasma levels of cocaine at 30 minutes after injection. Furthermore, atenolol and propranolol have equivalent effects on cardiac output (Schindler et al. 1992), and atenolol was less effective than propranolol at reducing cocaine-reinforced responding. In contrast to the present report and that of Goldberg and Gonzalaz (1976), other studies that have examined interactions between noradrenergic antagonists and cocaine have failed to report any changes in cocaine-related behaviors (de Wit and Wise 1977; Yokel and Wise 1976). In an early study by Yokel and Wise (1975) it was also reported that while decreasing amphetamine self-administration, propranolol had no effect on amphetamine-induced stereotypies.

\section{Pharmacology of Propranolol and Atenolol}

Propranolol has other pharmacological actions in addition to binding $\beta$-adrenergic receptors, including activity as a $5-\mathrm{HT}_{1}$ receptor antagonist and as a local anesthetic (Gilman et al. 1985; Middlemiss et al. 1977). The (+) propranolol isomer shares many properties with the 
racemic compound, except that it has a very low affinity for $\beta$-adrenergic receptors (Gilman et al. 1985; Middlemiss et al. 1977). (+) Propranolol has similar local anesthetic effects to propranolol and a significant, albeit relatively weaker, binding affinity for 5-HT receptors (Middlemiss et al. 1977). The fact that the $(+)$ isomer of propranolol had no effect on increasing the locomotor response to cocaine suggests that this action was due to the blockade of $\beta$-adrenergic receptors and not to a nonspecific effect of propranolol. Although it is still possible that the effect of propranolol could be due to the blockade of $5-\mathrm{HT}_{1}$ receptors, it has been reported that 5-HT agonists decrease stimulant self-administration behavior, and no effect, or an increase, has been found for 5-HT antagonists on cocaine self-administration (LaCosta and Roberts 1993; Peltier and Schenk 1993). Furthermore, $5-\mathrm{HT}_{1}$ antagonists are reported to decrease, not increase, the acute locomotor response to cocaine (King et al. 1993) and serotonin agonists increase accumbal dopamine transmission (Chen et al. 1991; Guan and McBride 1989). Together these data indicate that serotonergic effects of propranolol are unlikely to account for the present results.

Atenolol enters the brain in only limited amounts (Agon et al. 1991) and was unable to produce any enhancement in the locomotor response to cocaine or as dramatic a reduction in cocaine self-administration. This argues for a primarily central site of action by propranolol. However, atenolol is a relatively selective $\beta_{1}$ antagonist (Schindler et al. 1992). Therefore it is possible that peripheral $\beta_{2}$ receptors could partly mediate the effects of propranolol. At the very least it can be assumed that the locomotor enhancement was not due to the ability of the $\beta$-blockers to prevent cocaine-induced tachycardia (Schindler et al. 1992). However, further studies comparing central with peripheral administration of propranolol and atenolol are necessary to establish definitively a central site of action for propranolol and the selective involvement of $\beta$-receptor subtypes.

\section{CONCLUSIONS}

The data outlined indicate a role for $\beta$-adrenergic receptors in regulating dopaminergic activity within the mesolimbic system. Specifically, these data suggest that noradrenergic systems may serve to decrease dopamine output. Because propranolol alone did not increase dopamine levels above baseline, it is possible that $\beta$-adrenergic receptors may regulate the dopamine system only when dopamine transmission is altered. Antelman and Caggiula $(1977,1994)$ have similarly proposed that noradrenergic systems regulate dopamine output during stress. The regulation of mesolimbic dopamine transmission could arise via $\beta$-adrenergic receptors located in either the nucleus accumbens or ventral teg- mental area, as well as in other areas that project to these nuclei, such as the prefrontal cortex and amygdala (Rainbow et al. 1984). The precise anatomical loci whereby $\beta$-adrenergic receptors may regulate dopamine transmission is an interesting topic for further experimentation and may assist in understanding the actions of both psychostimulants and antidepressants.

\section{ACKNOWLEDGMENTS}

We would like to thank Jenny Baylon for assistance in preparing the manuscript and Ms. Stacy Hooks for assisting in maintaining the self-administration facility. This research was supported in part by a grant from the Alcohol and Drug Abuse Program at Washington State University and by USPHS grants \#MH-40817, \#DA-03906, and a Research Career Development Award \#DA-00158 (PWK).

\section{REFERENCES}

Agon P, Goethals P, Van Haver D, Kaufman JM (1991): Permeability of the blood-brain barrier for atenolol studied by positron emission tomography. J Pharmacol. 43:587-600

Antelman SM, Caggiula AR (1977): Norepinephrine-dopamine interactions and behavior. Science 195:646-653

Antelman SM, Caggiula AR (1994): Norepinephrine-dopamine interactions: One step beyond. In Briley M, Marien M (eds), Noradrenergic Mechanisms in Parkinson's Disease, Boca Raton, CRC Press, pp 127-138

Banerjee SP, Sharma VK, Kung-Cheung LS, Chanda SK, Riggi SJ (1979): Cocaine and d-amphetamine induce changes in central $\beta$-adrenoreceptor sensitivity: Effects of acute and chronic drug treatment. Brain Res 175:119-130

Caine SB, Koob GF (1993): Modulation of cocaine selfadministration in the rat through $\mathrm{D}-3$ receptors. Science 260:1814-1816

Carlsson C (1976): Propranolol in the treatment of alcoholism: A review. Postgrad Med J 52:166-167

Chen J, Van Praag HM, Gardner EL (1991): Activation of 5-HT3 receptor by 1-phenylbiguanide increases dopamine release in the rat nucleus accumbens. Brain Res 543:354-357

Crosby RD, Halikas JA, Carlson G (1991): Pharmacotherapeutic interventions for cocaine abuse: Present and future directions. In Cocaine, AIDS and Intravenous Drug Use, New York, The Haworth Press, pp 13-30.

Dahlstrom A, Fuxe K (1964): Evidence for the existence of monoamine-containing neurons in the central nervous system. I. Demonstration of monoamines in the cell bodies of brain stem neurons. Acta Physiol Scand 62:1-55

De Wit H, Wise RA (1977): Blockade of cocaine reinforcement in rats with the dopamine receptor blocker pimozide, but not with the noradrenergic blockers phenolamine or phenoxybenzamine. Can J Psychol 31:195-203

Dworkin SI, Smith JE (1992): Cortical regulation of selfadministration. Ann N Y Acad Sci 654:274-281

Dwoskin LP, Peris J, Yasuda RP, Philpott K, Zahniser NR (1988): Repeated cocaine administration results in super- 
sensitivity of striatal D-2 dopamine autoreceptors to pergolide. Life Sci 42:255-262

Gawin FH (1991): Cocaine addiction: Psychology and neurophysiology. Science 251:1580-1586

Gawin FH, Ellinwood EH, Jr (1988): Cocaine and other stimulants: Actions, abuse and treatment. $N$ Engl J Med 318:1173-1182

Gawin FH, Kleber HD (1984): Cocaine abuse treatment. Arch Gen Psychiat 41:903-910

Gilman AG, Goodman LS, Rall TW, Murad F (1985): The Pharmacological Basis of Therapeutics, ed 7, New York, Macmillan, pp 192-202

Goeders NE, McNulty MA, Mirkis S, McAllister KH (1989): Chlordiazepoxide alters intravenous cocaine self-administration in rats. Pharmacol Biochem Behav 33:859-866

Goldberg G, Gonzalaz G (1976): Effects of propranolol on behavior maintained under fixed-ratio schedules of cocaine injection or food presentation. J Pharmacol Exp Ther 198:626-634

Guan X-M, McBride WJ (1989): Serotonin microinfusion into the ventral tegmental area increases accumbens dopamine release. Brain Res Bull 23:541-547

Gunne LM, Anggard E, Johsson LE (1972): Clinical trials with amphetamine-blocking drugs. Psychiat Neurol Neurochir 75:225-226

Harris GC, Aston-Jones G (1994): $\beta$-adrenergic antagonists attenuate withdrawal anxiety in cocaine- and morphinedependent rats. Psychopharmacol 113:131-136

Heffner PG, Hartman JA, Sieden LS (1980): Feeding increases dopamine metabolism in rat brain. Science 208:1168-1170

Hooks MS, Colvin AC, Juncos JL, Justice JB, Jr (1992): Individual differences in basal and cocaine stimulated extracellular dopamine in the nucleus accumbens using quantitative microdialysis. Brain Res 587:306-312

Hubner CB, Koob GF (1990): The ventral pallidum plays a role in mediating cocaine and heroin self-administration in the rat. Brain Res 508:20-26

Kalivas PW, Duffy P (1993): Time course of extracellular dopamine and behavioral sensitization to cocaine. I. Dopamine axon terminals. J Neurosci 13:266-275

Kalivas PW, Stewart J (1991): Dopamine transmission in drug- and stress-induced behavioral sensitization. Brain Res Rev 16:233-244

Kalivas PW, Churchill L, Klitenick MA (1993): The circuitry mediating the translation of motivational stimuli into adaptive motor responses. In Kalivas PW, Barnes CD (eds), Boca Raton, CRC Press, pp 237-288.

King GR, Joyner C, Lee TH, Ellinwood EH, Jr (1993): Withdrawal from continuous or intermittent cocaine: Effects of NAN-190 on cocaine-induced locomotion. Pharmacol Biochem Behav 44:253-262

Koob GF (1992): Neuronal mechanisms of drug reinforcement. Ann N Y Acad Sci 654:171-191

Koob GF, Bloom FE (1988): Cellular and molecular mechanisms of drug dependence. Science 242:715-723

Kuczenski R, Segal SD (1988): Psychomotor stimulant-induced sensitization: Behavioral and neurochemical correlates. In Kalivas PW, Barnes CD (ed), Sensitization in the Nervous System, Caldwell, NJ, Telford Press, pp 175-205
LaCosta S, Roberts DCS (1993): MDL 72222, ketanserin and methysergide pretreatments fail to alter breaking points on a progressive ratio schedule reinforced by intravenous cocaine. Pharmacol Biochem Behav 44:161-165

Le Moal M, Simon H (1991): Mesocorticolimbic dopaminergic network: Functional and regulator roles. Physiol Rev 71:155-234

Markou A, Koob GF (1991): Post cocaine anhedonia. An animal model of cocaine withdrawal. Neuropsychopharmacol 4:17-26

Middlemiss DN, Blakeborough L, Leather SR (1977): Direct evidence for an interaction of $b$-adrenergic blockers with the 5-HT receptor. Nature 267:289-290

Mogenson GJ, Brudzynski SM, Wu M, Yang CR, Yim CCY (1993): From motivation to action: A review of dopaminergic regulation of limbic-nucleus accumbens-pedunculopontine nucleus circuitries involved in limbicmotor integration. In Kalivas PW, Barnes CD (ed), Boca Raton, CRC Press, pp 193-236

Parsons LH, Justice JB, Jr (1993): Serotonin and dopamine sensitization in the nucleus accumbens, ventral tegmental area and dorsal raphe nucleus following repeated cocaine administration. J Neurochem 61:1611-1619

Patrick SL, Thompson TL, Walker JM, Patrick RL (1991): Concomitant sensitization of amphetamine-induced behavioral stimulation and in vivo dopamine release from rat caudate nucleus. Brain Res 538:343-346

Paxinos G, Watson C (1986): The Rat Brain in Stereotaxic Coordinates, ed 2. New York, Academic Press.

Peltier P, Schenk S (1993): Effects of serotonergic manipulation on cocaine self-administration in rats. Psychopharmacol 110:390-394

Pettit HO, Justice JB Jr (1990): Effect of dose on cocaine selfadministration behavior and dopamine levels in the nucleus accumbens. Brain Res 539:94-102

Pettit HO, Ettenberg A, Bloom FE, Koob GF (1984): Destruction of dopamine in the nucleus accumbens selectively attenuates cocaine but not heroin self-administration in rats. Psychopharmacol 84:167-173

Pettit HO, Pan H-T, Parsons LH, Justice JB, Jr (1990): Extracellular concentrations of cocaine and dopamine are enhanced during chronic cocaine administration. J Neurochem 55:798-804

Rainbow TC, Parsons B, Wolfe BB (1994): Quantitative autoradiography of $\beta_{1}$ - and $\beta_{2}$-adrenergic receptors in rat brain. Proc Natl Acad Sci U S A 81:1585-1589

Reith MEA, Meisler BE, Sershen H, Lajtha A (1986): Structural requirements for cocaine congeners to interact with dopamine and serotonin uptake sites in mouse brain and to induce stereotyped behavior. Biochem Pharmacol 35:1123-1129

Ritz MC, Cone EJ, Kuhar MJ (1990): Cocaine inhibition of ligand binding at dopamine, norepinephrine and serotonin transporters: A structure-activity study. Life Sci 46:635-645

Roberts DCS, Koob GF (1982): Disruption of cocaine selfadministration following 6-hydroxydopamine lesions of the ventral tegmental area in rats. Pharmacol Biochem Behav 17:901-904 
Roberts DCS, Vickers G (1984): Atypical neuroleptics increase self-administration of cocaine: An evaluation of a behavioral screen for antipsychotic activity. Psychopharmacol 82:135-139

Robertson MW, Leslie CA, Bennett JP, Jr (1991): Apparent synaptic dopamine deficiency induced by withdrawal from chronic cocaine treatment. Brain Res 538:337-340

Robinson TE, Berridge KC (1993): The neural basis of drug craving: An incentive-sensitization theory of addiction. Brain Res Rev 18:247-291

Robinson TE, Wishaw IQ (1988): Normalization of extracellular dopamine in the striatum following recovery from a partial unilateral 6-OHDA lesion of the substantia nigra: A microdialysis study in freely moving rats. Brain Res 450:209-224

Rossetti ZL, Hmaidan Y, Gessa GL (1992): Marked inhibition of mesolimbic dopamine release: A common feature of ethanol, morphine, cocaine and amphetamine abstinence in rats. Eur J Pharmacol 221:227-234

Schindler CW, Tella SR, Goldberg SR (1992): Adrenoceptor mechanisms in the cardiovascular effects of cocaine in conscious squirrel monkeys. Life Sci 51:653-660

Siegel RK (1985): Treatment of cocaine abuse: Historical and contemporary perspectives. J Psychoactive Drugs 17:1-9
Sorg BA, Kalivas PW (1991): Behavioral and neurochemical cross-sensitization between footshock stress and cocaine. Brain Res 559:29-36

Swanson LW (1982): The projections of the ventral tegmental area and adjacent regions: A combined fluorescent retrograde tracer and immunofluorescence study in the rat. Brain Res Bull 9:321-353

Weiss F, Markou A, Lorang MT, Koob GF (1992): Basal extracellular dopamine levels in the nucleus accumbens are decreased during cocaine withdrawal after unlimitedaccess self-administration. Brain Res 593:314-318

Wise RA, Rompre PP (1989): Brain dopamine and reward. Ann Rev Psychol 40:191-215

Yokel RA, Wise RA (1975): Increased lever pressing for amphetamine after pimozide in rats: Implications for a dopamine theory of reward. Science 187:547-549

Yokel RA, Wise RA (1976): Attenuation of intravenous amphetamine reinforcement by central dopamine blockade in rats. Psychopharmacol 48:311-318

Zito KA, Vickers G, Roberts DCS (1985): Disruption of cocaine and heroin self-administration following kainic acid lesions of the nucleus accumbens. Pharmacol Biochem Behav 23:1029-1036 